\title{
Bond behaviour in lime-based textile reinforced mortars
}

\author{
B. Ghiassi \\ Centre for Structural Engineering and Informatics, Faculty of Engineering, University of Nottingham, Nottingham, \\ $U K$
}

\author{
A. Dalalbashi \\ Department of Civil Engineering, ISISE, University of Minho, Azurém, Guimarães, Portugal \\ D.V. Oliveira \\ Department of Civil Engineering, ISISEIB-S, University of Minho, Azurém, Guimarães, Portugal
}

\begin{abstract}
Application of textile-reinforced mortar (TRM) composites have for strengthening of existing structures or for production of new thin structural elements has attracted a growing recent attention. TRMs are made of continuous fibres (in the form of fabric or mesh) embedded in an inorganic matrix forming a composite material. The large variety of available fabric (glass, steel, basalt, $\mathrm{PBO}$, etc.) and mortar types (cement-based, lime-based, etc.) leads to a wide range of mechanical properties making these composites suitable for fit-for-purpose design applications. Due to mechanical and hygrothermal compatibility issues, limebased TRMs are the preferred choice for application to existing masonry and historical structures. Meanwhile, cement-based TRMs are usually employed for application to existing concrete or new masonry structures. The main characteristic behaviour of these composites is the tension stiffening response and distributed cracking under tensile loads which are highly influenced by the fabric-to-mortar bond behaviour. Fundamental understanding of this mechanism (the fabric-to-mortar bond behaviour) and parameters affecting that are therefore of critical importance of designing TRM composites with desired properties. This paper presents and overview of the recent studies we performed during the lat years for better udnertanding this mechanism.
\end{abstract}

\section{INTRODUCTION}

The special feature of textile reinforced mortar (TRM) composites and their advantages with respect to fibre-reinforced polymers (FRPs) have made them an interesting choice for externally bonded reinforcement of masonry and reinforced concrete structures (Triantafillou \& Papanicolaou 2005, Papanicolaou et al. 2007, Carozzi \& Poggi 2015, Mazzuca et al. 2019).

Textile reinforced mortar (TRM) and textile reinforced concrete (TRC), composed of continuous fibres embedded in mortar or concrete, are novel composite materials recently received an extensive attention for repair of existing masonry and concrete structures and for construction of new structural and non-structural components such as facades, or light structures. These composites show a considerable tensile strength with a pseudo-ductile response, owing to their relatively large post-cracking deformation capacity and multiple cracking response before failure. The large variety of available fabrics and mortar types allow development of TRM composites with a large range of mechanical properties (Caggegi et al. 2017, De Santis et al. 2017, Leone et al. 2017). However, in order to fully utilize the potential of these materials, it is necessary to understand the mechanisms responsible for structural behaviour of these composites and in particular the role of fabricto-mortar bond behaviour on their response.

TRMs used for strengthening of masonry structures are usually composed of glass, steel, basalt, PBO or other natural/synthetic fabrics embedded in cementitious or lime-based matrices. While cementitious matrices are preferred for strengthening of new (high quality) masonry structures, lime-based mortars are the preferred choice for strengthening of historical or weak structures due to their hygrothermal and mechanical compatibility.

While several studies have been devoted to investigation and development of TRC composites, there are still several open issues regarding the mechanics and durability of these composites. Meanwhile, investigations on TRMs for strengthening of masonry and concrete structures are very recent. The existing experimental and numerical modelling studies in this field, and consequently understanding of the mechanisms affecting their performance, are therefore limited.

This paper presents an overview of the recent experimental and analytical investigations on the fabric-to-mortar bond behaviour in TRM composites 
commonly used and recommended for strengthening of masonry structures. (Ghiassi et al. 2016, Dalalbashi et al. 2018a, b, Dalalbashi et al. 2019). The role of a range of critical parameters, such as test setup, fabric type, embedded length and mortar age, on the bond behaviour is investigated and discussed.

\section{TRM SYSTEMS USED IN THIS STUDY}

A range of fabric and mortar types are available in the market for development of TRMs. TRM composites commonly used for strengthening of masonry structures are usually made of glass, steel, basalt or PBO embedded in a cementitious or a lime-based matrix. Lime-based mortars are the preferred choice when strengthening of existing weak or historical structures are of concern.

The experimental results presented in this paper are performed on two commercially available limebased TRMs: a steel-based and a glass-based TRM.

The steel-based TRM was composed of a commercially available pure natural NHL 3.5 lime and mineral geo-binder with a 28-day compressive strength of $9.53 \mathrm{MPa}(\mathrm{CoV}=11.1 \%)$ and a flexural strength of $2.54 \mathrm{MPa}(\mathrm{CoV}=9.6 \%)$ as the matrix and a unidirectional ultra-high tensile steel sheet (GeoSteel G600, density of $670 \mathrm{~g} / \mathrm{m}^{2}$ and effective area of one cord of $0.538 \mathrm{~mm}^{2}$ ) as the reinforcing material. Each steel fibre is made by twisting five individual wires together, three straight filaments wrapped by two filaments at a high twist angle, forming a uniform cord and a non-smooth surface that ensures a good mechanical bond with the matrix. The tensile strength, elastic modulus and ultimate strain of the steel cords were experimentally obtained as $2972 \mathrm{MPa}, 189 \mathrm{GPa}$ and $1.88 \%$, respectively.

The glass-based TRM was made of a commercially available hydraulic lime-based mortar (Planitop HDM Restauro) with a 28-day compressive strength of 7.1 $\mathrm{MPa}(\mathrm{CoV}=10.5 \%)$ and a flexural strength of 4.71 $\mathrm{MPa}(\mathrm{CoV}=7.8 \%)$ as the matrix and a woven biaxial fabric mesh made of an alkali-resistance fiberglass (Mapegride G220) with a mesh size and area per unit of width area equal to $25 \times 25 \mathrm{~mm}^{2}$ and $35.27 \mathrm{~mm}^{2} / \mathrm{m}$ as the reinforcing material. The tensile strength, elastic modulus and ultimate strain of the glass yarns were experimentally obtained as $875 \mathrm{MPa}, 65.94 \mathrm{GPa}$ and $1.77 \%$, respectively.

\section{BOND CHARACTERIZATION TEST SETUP}

Pull-out tests are the most common testing methodology for characterization of the interface properties in composite materials made of brittle matrices (such as TRC or TRMs). Different pull-out testing configurations have been proposed and adapted by different researchers for performing these tests. These can be generally categorized into pull-pull and pull-push

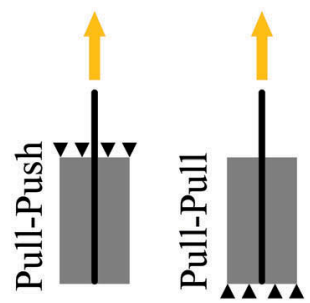

Figure 1. Schematic presentation of the pull-pull and pull-push testing configurations.

testing configurations (Boundary conditions and load application method schematically shown in Figure 1). Some discussions can be found in the literature on the advantages and disadvantages of each of these testing configurations. While it is difficult to draw conclusions on the most suitable test setup, it seems that pull-push tests can be performed with more accuracy and control, but pull-pull tests introduce a more realistic representation of the stress state at the crack surface.

To evaluate the effect of test setup on the experimental force-slip curves, experimental tests were performed on steel-based TRM samples under both testing configurations as presented in Figure 2 (Dalalbashi et al. 2018a). In both cases the yarn free length was embedded in an epoxy resin block to facilitate the gripping and slip measurements during the tests. This strategy also helps in a significant reduction of variations in the experimental results compared to previous tests in which the free yarn length was not embedded as in Ghiassi et al. (2016).

The details of the experimental results and discussions can be found in Dalalbashi et al. (2018a). The results showed specimens tested under a pull-pull configuration present a higher peak debonding load but a lower initial stiffness compared to specimens tested under pull-push test setup. These differences are, in fact, due to the differences in the boundary condition and stress distributions in the samples tested under these two configurations. Clearly this should be

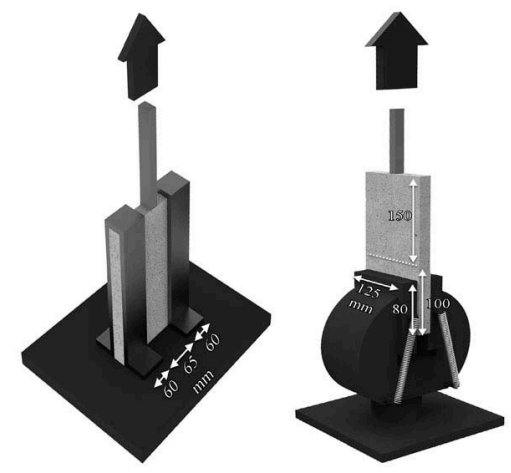

Figure 2. Pull-pull and pull-push test setups. 
considered when pull-out results obtaeind from different test setups are compared. Dalalbashi et al. (2018a) showed that when the role of boundary conditions are accurately considered in the numerical or analytical simulations, the extracted bond-slip laws, however, will only show a slight difference. We also observed that the experimental results obtained from the pullpush testing methodology are more repeatable and easier to control and for this reason we used this test setup in our further studies.

\section{YARN EMBEDDED LENGTH}

The role of yarn embedded length on the pull-out results was investigated by performing pull-put tests on samples with yarn (or cord) embedded lengths of $50 \mathrm{~mm}, 100 \mathrm{~mm}, 150 \mathrm{~mm}$ and $200 \mathrm{~mm}$ for the steelbased TRM and samples with embedded lengths of $50 \mathrm{~mm}, 75 \mathrm{~mm}$ and $100 \mathrm{~mm}$ for the glass-based TRM. The tests were performed under a pull-push testing configuration and under displacement controlled condition by pulling the yarns (the epoxy block) with a displacement rate of $1.0 \mathrm{~mm} / \mathrm{min}$.

In the steel-based TRM samples (Figure 3), the failure of the samples was yarn slippage from the mortar in all considered embedded lengths. The pullout curves follow the typical pull-out response of fibres embedded in brittle matrices and can be divided into an initial linear stage, then a nonlinear stage until reaching the peak load, then a drop in the load followed by a slip hardening effect and finally softening of the force until the end of the tests.

It can be observed that peak loads increase until an embedded length of $150 \mathrm{~mm}$ and thereafter remain constant. Also, the slope of the slip hardening region increases with increment of the embedded length. Obviously, the toughness (defined as the are under the pull-out curves is also increased with embedded length.

In the glass-based TRM samples, on the other hand, the failure of the samples was yarn slippage at

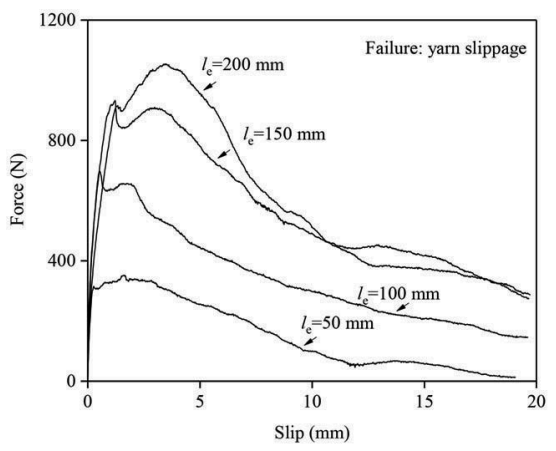

Figure 3. Pull-out response of the steel-based TRM with different embedded lengths.

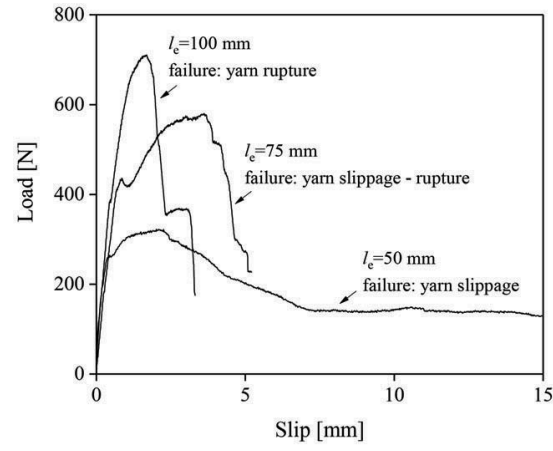

Figure 4. Pull-out response of the glass-based TRM with different embedded lengths.

$50 \mathrm{~mm}$ embedded length which gradually changed to yarn tensile rupture until the embedded length of $100 \mathrm{~mm}$. This change of failure mode is also obvious in the experimental force-slip curves (Figure 4). Again, where slippage of the yarn has occurred (i.e. in embedded length of $50 \mathrm{~mm}$ and $75 \mathrm{~mm}$ ), a slip hardening is observed in the results.

\section{MORTAR AGE}

It is clear that the mortar age (or hydration degree) can have a significant influence on the bond performance. With increasing the mortar hydration degree, the bond performance is enhanced as stronger chemical bonds are formed between the fabric and the mortar. Meanwhile the mechanical properties of mortar is improved which affects the mechanical bond as well. Most of the existing literature on characterization of interfaces between fibres and brittle matrices is devoted to cementitious matrices (mortars and concert). Consequently, in most of these studies the pull-out tests are performed after 28 days of curing that is a standard curing time for cementitious matrices for achieving a high cement curing degree.

This curing age, however, might not be suitable for lime-based matrices, especially due to the fact that these matrices have a slower hydration rate. To evaluate this hypothesis, pull-out tests were performed on both steel-based and glass-based TRM systems at different curing ages ranging from 15 to 180 days (Figure 5 and 6 ).

In the case of steel-based TRM, the results does not show a specific trend with increasing the mortar age. That means that a considerable enhancement of the bond performance is observed from 15 to 30 days of curing, and thereafter, setbacks and enhancements are observed with no correlation to the mortar age. The range of variation of the average pull-out curves, however, seems to be in the same range as the common variation of the experimental results 


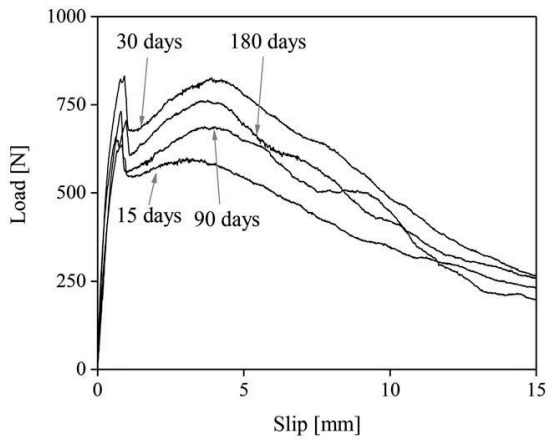

Figure 5. Pull-out response of the steel-based TRM tested at different mortar ages.

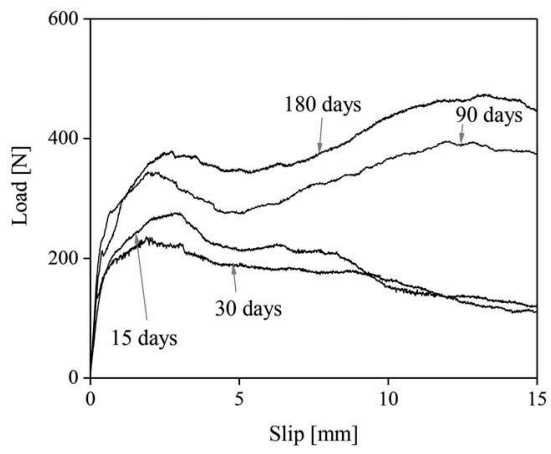

Figure 6. Pull-out response of the glass-based TRM tested at different mortar ages.

observed in pull-out tests performed on identical samples and therefore concluding that in this TRM system, a 30 days aging is a suitable test age seems reasonable.

In the case of glass-based TRM, a clear enhancement of the bond performance is observed until 180 days of mortar curing. Interestingly, the samples tested at 90 and 180 days, show two consecutive slip hardening effects in the pull-put curves. In this case, it is clear that a 30 -day curing age is not sufficient for obtaining a response that is representative of the long-term pull-out behaviour of this TRM system.

The results clearly show the importance of mortar age in evaluation of the bond performance in TRM systems. The importance of this difference on the mechanical properties of TRM components (such as tensile strength or tension stiffening) is not clear and require further investigations. The variability of the available mortar types makes definition of a standard testing age complicated and also inaccurate. The results also show that comparison of the bond performance between TRMs made of different mortar should be made with special care and after consideration of the mortar hydration degree.

In the case of TRM systems studied here, there seems to be a clear correlation between the bond

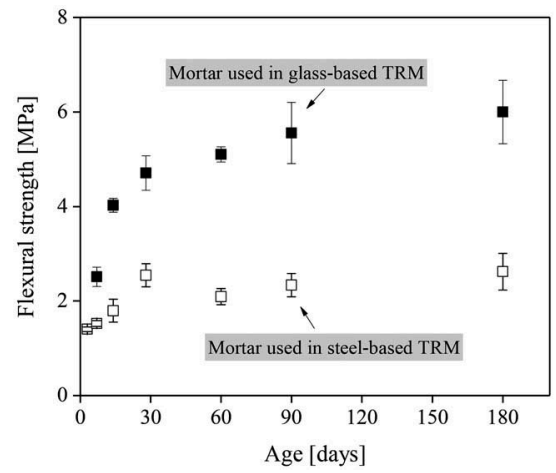

Figure 7. Average flexural strength of the mortars at different ages.

performance and flexural strength of the mortar in each TRM system. Figure 7 shows that the flexural strength of the mortar used in the steel-based TRM reaches its peak value at the age of 30 days and after that it fluctuates (it is increased and decreased) around this peak flexural strength. This is consistent with the observed bond performance (shown in Figure 5). In the case of glass based TRM, the mortar flexural strength is increased until 180 days that is also consistent with the observed enhancement of the bond performance in this system.

\section{YARN VS FABRIC}

To address the effect of fabric type on the bond performance, the differences between the pull-out response of single yarn (or cord) and fabric are investigated in this section for both of the studied systems.

In the glass-based TRM, as a bidirectional glass fabric was used, the pull-out tests were replicated on samples with a $50 \mathrm{~mm}$ embedded length made of a single yarn, a single yarn + transverse yarns and two yarns + transverse yarns.

The average experimental force slip curves (presented in Figure 8 in terms of the load/yarn) shows the significant effect of the transverse yarn on the bond behaviour (mainly post-peak response and toughness) in this particular system. Obviously, the effect of transverse yarns is dependent on the type of junction used for connecting the longitudinal and transverse yarns and can be different depending on the type of fabric used. These results, however, show in bidirectional fabrics the role of transverse yarns can be significant in the bond behaviour and need to be considered in the design or in extraction of the bond-slip laws.

In the steel-based TRM, as a unidirectional fabric was used, the pull-out tests were replicated on samples with a $150 \mathrm{~mm}$ embedded length made of a single cord, two cords four cords. 


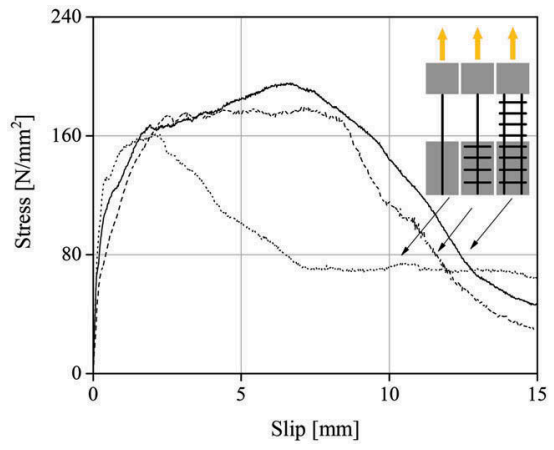

Figure 8. Fabric vs yarn pull-out response in glass-based TRM.

Interestingly, it can be observed that with increasing the number of cords, the pull-out curves show a smaller bond strength and toughness. This observation can be attributed to the group effect and the overlapping of the effect bond area around each cord on each other.

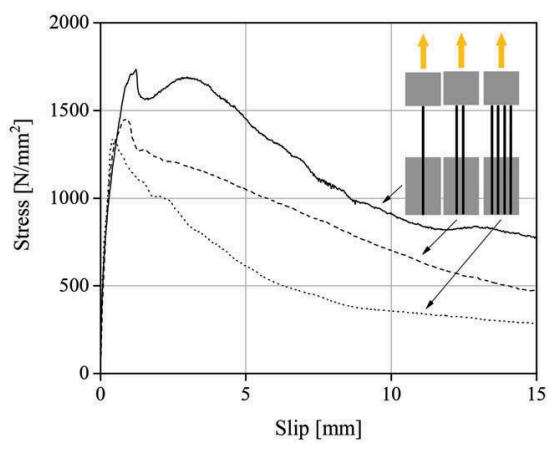

Figure 9. Fabric vs yarn pull-out response in steel-based TRM.

\section{CONCLUSIONS}

This paper presented an overview of recent studies on the bond performance in lime-based TRM composites. Pull-out tests were used for investigating the role of a number of critical parameters on the bond performance in these composites.

The focus was particularly on the role of test setup, embedded length, TRM type, mortar age and the differences between the yarn and fabric bond behaviour. The results although still limited and preliminary showed the important of these factors on the bond behaviour in these systems and the need for performing further comprehensive studies for fundamentally understanding the role of each factor.

\section{ACKNOWLEDGEMENTS}

The second author wish to thank the Portuguese Scientific Foundation (FCT) for the financial support through grant SFRH/BD/131282/2017.

\section{REFERENCES}

Carozzi, F.G. \& Poggi, C. 2015. Mechanical properties and debonding strength of Fabric Reinforced Cementitious Matrix (FRCM) systems for masonry strengthening. Composites Part B: Engineering 70: 215-230.

Caggegi, C. et al. 2017. Experimental analysis on tensile and bond properties of $\mathrm{PBO}$ and aramid fabric reinforced cementitious matrix for strengthening masonry structures. Composites Part B: Engineering 127.

De Santis, S. et al. 2017. Round Robin Test on tensile and bond behaviour of Steel Reinforced Grout systems. Composites Part B: Engineering 127.

Dalalbashi, A. et al. 2018a. Effect of test setup on the fiberto-mortar pullout response in TRM composites: experimental and analytical modeling. Composites Part B: Engineering 143: 250-268.

Dalalbashi, A. et al. 2018b. Fiber-to-mortar bond behavior in TRM composites: effect of embedded length and fiber configuration. Composites Part B: Engineering 152: 43-57.

Dalalbashi, A. et al. 2019. Textile-to-mortar bond behaviour in lime-based textile reinforced mortars. Construction and Building Materials 227: 116682.

Ghiassi, B. et al. 2016. Multi-level characterization of steel reinforced mortars for strengthening of masonry structures. Materials and Design 110: 903-913.

Leone, M. et al. 2017. Glass fabric reinforced cementitious matrix: Tensile properties and bond performance on masonry substrate. Composites Part B: Engineering 127.

Mazzuca, S. et al. 2019. Mechanical Characterization of Steel-Reinforced Grout for Strengthening of Existing Masonry and Concrete Structures. Journal of Materials in Civil Engineering 31(5): 04019037.

Papanicolaou, C.G. et al. 2007. Textile reinforced mortar (TRM) versus FRP as strengthening material of URM walls: out-of-plane cyclic loading. Materials and Structures 41(1): 143-157.

Razavizadeh, A. et al. 2014. Bond behavior of SRG-strengthened masonry units: Testing and numerical modeling. Construction and Building Materials 64: 387-397.

Triantafillou, T.C. \& Papanicolaou, C.G. 2005. Textile reinforced mortars (TRM) versus fiber reinforced polymers (FRP) as strengthening materials of concrete structures. Spec. Publ. 230: 99-118. 